\title{
Letters
}

Website: bmj.com

Email: letters@bmj.com

\section{Risk of adverse birth outcomes near landfill sites}

Evidence suggests that it is probably safe for fetuses to develop near landfill sites

EDITOR-Elliott et al report a large geographical study of adverse birth outcomes in populations living near landfill sites. ${ }^{1}$ They conclude that there are small excess risks of congenital anomalies and low birth weight in such populations.

Although they advise caution when interpreting their results, the study is nevertheless hailed by the press and by environmental groups as evidence that living near such sites is hazardous to health. ${ }^{2}$ The concerns felt by parents, often with no opportunity to move elsewhere, are fuelled, and perhaps on no grounds. Scientists contribute to the media generated intrigue in subtle ways. For example, the description of the paper in an editorial by McNamee and Dolk as a report "on the risks to fetuses associated with residence" when "a study of the statistical association between reported anomalies and residence" would have been more accurate and less sensationalist. ${ }^{3}$ Health authorities are left to pick up the pieces when a story breaks, with no advance warning, about a landfill site in their area.

Another interpretation of the results of Elliott et al is that this essentially negative

\section{Advice to authors}

We prefer to receive all responses electronically, sent directly to our website. Processing your letter will be delayed unless it arrives in an electronic form.

We are now posting all direct submissions to our website within 24 hours of receipt and our intention is to post all other electronic submissions there as well. All responses will be eligible for publication in the paper journal.

Responses should be under 400 words and relate to articles published in the preceding month. They should include $\leqslant 5$ references, in the Vancouver style, including one to the BMJ article to which they relate. We welcome illustrations.

Please supply each author's current appointment and full address, and a phone or fax number or email address for the corresponding author. We ask authors to declare any competing interest. Please send a stamped addressed envelope if you would like to know whether your letter has been accepted or rejected.

Letters will be edited and may be shortened.

bmj.com

letters@bmj.com study goes some way to reassuring other scientists who have been studying this question that it is probably safe for fetuses to develop near such sites. Any scientist who has any experience of multivariate epidemiological analysis would have to admit that such small and inconsistent excesses and deficits, even though significant, could well be attributable to inadequately adjusted social deprivation, to name but one of many important confounders. The fact that there was no increase after the landfill sites became operational, and a significant deficit of anomalies around landfill sites in Scotland, must leave even the most determined author feeling uneasy about suggesting a causal association. Epidemiological techniques used in this study are blunt instruments unlikely to detect subtle or unidentified effects.

Perhaps it is time for epidemiologists to admit that their tools are inadequate to answer this question. Other scientists should take this forward by developing better techniques to identify any putative agents in the gas emissions, leachates, and soil that may be of sufficiently high concentrations to affect human health.

Many of these landfill sites are unattractive and foul smelling, attracting seagulls and peppering the landscape with rubbish. More imaginative long term wastemanagement solutions are long overdue. Consideration should be given to refusing planning permission for new build housing adjacent to landfill sites.

Helene Irvine consultant in public health medicine (communicable disease and environmental health) helene.irvine@gghb.scot.nhs.uk

Harry Burns director of public health

Greater Glasgow NHS Board, Glasgow G3 8YU

1 Elliott P, Briggs D, Morris S, de Hoogh C, Hurt C, Jensen TK, et al. Risk of adverse birth outcomes in population living near landfill sites. BMJ 2001;323:363-8. (18 August) 2 Foster K. Landfill sites blamed for birth defects. Scotsma 2001 Aug 17:1 (col 1).

McNamee R, Dolk H. Does exposure to landfill waste harm the fetus? BMJ 2001;323:351-2. (18 August.)

4 Greater Glasgow Health Board Investigation of possible ill-health near a landfil site in East Glasgow G possible Greater Glasgow Heath Boas 1999. (Board Glasgow: 99/136(b).)

Risks from landfill sites can be presented in alternative ways

EDITOR-The presentation of risks in relative terms does not help individuals, or the population, to understand the risk to themselves. Let us assume that the risks identified by Elliott et al are not due to unmeasured confounding.

By taking the absolute risk in the reference area into account, we can translate the relative risk of 1.01 for all anomalies combined to one extra anomaly among 5903 who were exposed to living within $2 \mathrm{~km}$ of a landfill site. This can be set against the baseline population risk of one anomaly among each 59 individuals. The relative risk of 1.05 for neural tube defects can similarly be expressed as one extra defect among 35714 exposed people, against the baseline risk of one per 1786 in the general population. Extending this further, we can calculate the number of the total population among whom one extra anomaly will be produced by the presence of landfill sites (to which $55 \%$ of the population are exposed within $2 \mathrm{~km}$ )-this is termed the population impact number. ${ }^{2}$ For all anomalies it is 10733 and for spina bifida it is 64935 .

Should the evidence be thought to be robust enough, the individual and the community can use terms beyond the relative risk to help with decision making.

Dick Heller professor of public health

Evidence for Population Health Unit, School of Epidemiology and Health Sciences, University of Manchester, Manchester M13 9PT

dick.heller@man.ac.uk

1 Elliott P, Briggs D, Morris D, de Hoogh C, Hurt C, Jensen TK, et al. Risk of adverse birth outcomes in population living near landfill sites. BMJ 200 1;323:363-8. (18 August.) 2 Heller RF, Dobson AJ. Disease impact number and population impact number: a population perspective to measures of risk and benefit. BMJ 2000;321:950-2

\section{News stories were handled badly}

EDITOR-Editor's choice of 18 August refers to the difficulty of transmitting medical stories to the general press. ${ }^{1}$ The potential press interest in the article by Elliott et al on birth defects and landfill sites is noted, and a thoughtful and balanced editorial by McNamee and Dolk accompanies the paper. $^{23}$ The relevant paragraph in This week in the $B M J$ then carries the headline: "People living near landfill sites have an increased risk of adverse birth outcomes." The lay press has, of course, not been slow to pick up this headline-see, for example, the front page of the Guardian on 18 August. ${ }^{4}$

The whole point of the editorial by McNamee and Dolk is that we do not know whether living near a landfill site is a risk for birth defects or not-the study by Elliott et al is very important but requires further investigation. What hope is there of curtailing the media's obsession with medical scare stories if even a respected medical journal is 
prepared to highlight a story by using a sensational headline?

Roger A Fisken consultant physician

Friarage Hospital, Northallerton, North Yorkshire DL6 1JG

daardon@yahoo.com

1 Editor's choice. The passage from the $B M J$ to the Scunthorpe Daily Echo or CNN. BMJ 2001;321 (7309). (18 August.)

2 Elliott P, Briggs D, Morris D, de Hoogh C, Hurt C, Jensen TK, et al. Risk of adverse birth outcomes in population living near landfill sites. BMJ 2001;323:363-8. (18 August)

3 McNamee R, Dolk H. Does exposure to landfill waste harm the fetus? BMJ 2001;323:351-2. (18 August.)

4 Boseley S. Birth defect risks from landfill sites. Guardian 2001 Aug 17:1.

\section{Local registers provide more accurate} information

EDITOR-Elliott et al in their investigation of the risk of adverse outcome associated with residence near landfill sites conclude that one explanation for the finding of a small excess risk of congenital anomalies and low and very low birthweight babies, is a data artefact. ${ }^{1}$ Poor ascertainment and low levels of reporting to the national congenital anomaly system at the Office for National Statistics in England and Wales is, as Elliott et al say, well recognised.

Around $45 \%$ of births in England and all in Wales are now covered by local congenital anomaly registers, some of which exchange data electronically with the Office for National Statistics. These registers, which actively search for cases and have multisource ascertainment, provide much more accurate data than routine returns of form SD56 to the office. In Oxfordshire we have shown that many serious anomalies, such as heart defects, do not get reported but minor ones, such as clicking hip (on the office's exclusion list), do. In 1999 less than 30\% of registerable anomalies occurring around Oxford were notified to the Office for National Statistics. Our local health authority seems unconcerned by this because reporting congenital anomalies is not a statutory requirement and therefore, it seems, not a priority.

The findings of the study by Elliott et al may well cause pregnant women to become more anxious. It is too easy to report that data may be flawed. Elliott et al would have been well advised to restrict their analysis to those areas served by recognised registers. We do pregnant women a disservice by raising concerns from studies using flawed data (garbage in, garbage out). The patchy reporting of anomalies is now being highlighted by the British Isles Network of Congenital Anomaly Registers (BINOCAR), with the aim of improving surveillance of congenital anomalies for the whole of England and Wales. This is crucial not only for investigating potential teratogens but also for monitoring new prenatal screening and diagnostic tests.

Patricia A Boyd clinical geneticist Patricia.boyd@orh.nhs.uk

Paul F Chamberlain consultant obstetrician Oxford Prenatal Diagnosis Unit, Women's Centre Radcliffe Hospital, Oxford OX3 9DU

1 Elliott P, Briggs D, Morris D, de Hoogh C, Hurt C, Jensen TK, et al. Risk of adverse birth outcomes in population living near landfill sites. BMJ 2001;323:363-8. (18 August.)

\section{Diagnosing myocardial infarction}

\section{Randomised controlled trial and economic evaluation of a chest pain unit are in progress}

EDITOR-Acute chest pain is an important but neglected, problem in the United Kingdom. ${ }^{1}$ Emerging diagnostic approaches, such as the use of ST segment monitoring in emergency departments, new cardiac markers, and chest pain units have been extensively investigated in the United States. ${ }^{2-4}$ Yet evaluation in the United Kingdom has progressed little beyond audit. Herren et al should therefore be congratulated for embarking on rigorous evaluation of this problem. ${ }^{5}$ The protocol they describe has impressive diagnostic performance for myocardial infarction. There are, however, several reasons why we cannot assume that this will lead to improved patient care and cost effectiveness.

Assessment of acute chest pain requires more than simply ruling out myocardial infarction. Chest pain units in the United States typically provide provocative cardiac testing to stratify their patients further by risk. Immediate exercise stress testing is feasible in British emergency departments and is provided to patients within six hours of attendance at the Northern General Hospital in Sheffield.

The Manchester study enrolled 383 patients over the course of one year. This represents approximately one patient per day and accounts for only a smal proportion of attendances with chest pain to an urban emergency department. In these circumstances the selection process may be as important as the diagnostic protocol itself. A substantial proportion of patients have known coronary heart disease and present with characteristic angina-type pain, but have no diagnostic changes on electrocardiography. Were these patients included in the study? If not, how were they excluded?

Without a control group it is impossible to know how the cohort described would be managed if there were no chest pain unit. American studies of chest pain units have shown cost savings compared with a control group that is routinely admitted and shown improved effectiveness compared with control groups with substantial discharge rates. ${ }^{4}$ A meaningful comparison should, however, reflect current routine practice-patients admitted or discharged according to the clinicians' judgment.

A randomised controlled trial incorporating such a control group is currently in progress at the Northern General Hospital in Sheffield. An identical gold standard to that used in Manchester (troponin T) is being used to compare diagnostic accuracy. Evaluation also includes cardiac events over six months, quality of life, health utility, patient satisfaction, and cost effectiveness Until such data are available chest pain units should be considered to be of unproved value in the United Kingdom.

Steve Goodacre health services research fellow Medical Care Research Unit, University of Sheffield, Sheffield S1 4DA

s.goodacre@sheffield.ac.uk

Francis Morris consultant in accident and emergency medicine

Stephen Campbell consultant cardiologist Northern General Hospital, Sheffield S5 7AU

Deborah Quinney research fellow

Simon Capewell chair of clinical epidemiology

Department of Public Health, University of

Liverpool, Liverpool L69 3BG

1 Capewell S, McMurray JJV. "Chest pain-please admit": is there an alternative? BMJ 2000;320:951-2.

2 Fesmire FM, Percy RF, Bardoner JB, Wharton DR, Calorer Calhoun FB. Usefulness of automated serial 12-lead ECG monitoring daring the inital emergency department evaluation of
1998;31:3-11.

3 American College of Emergency Physicians. Clinical policy: Critical issues in the evaluation and management of adult patients presenting with suspected acute myocardial infarction or unstable angina: Serum marker analysis in acute myocardial infarction. Ann Emerg Med 2000;35: 521-544.

4 Goodacre SW. Should we establish chest pain observation units in the United Kingdom? A systematic review. J Accid Emerg Med 2000;17:1-6.

5 Herren KR, Mackway-Jones K, Richards CR, Seneviratne CJ France MW Cotter L Diagnostic cohort study Is it possible to exclude a dit sible to exclude a diagnosis of myocardial damage within six hours of admission to an emergency department? BMJ
2001:323:372.(18 August.)

\section{Additional tools may help to identify} patients at low risk

EDIToR-The major flaw of the article by Herren et al is that it proposes that ruling out myocardial infarction allows a doctor to assume that the patient is at low risk and may be discharged from the emergency centre. ${ }^{1}$ Perhaps these patients are at low risk of myocardial infarction but not coronary artery disease. Another study, using a stress test or minimally invasive angiography, could elucidate this point

In our unit we typically use a period of 9-12 hours of serial cardiac enzyme measurements (CPK-mb or troponin i), in conjunction with ST segment monitoring, to rule out patients with myocardial infarction. The patient then has a stress thallium test or, at the preference of the cardiologist, heart catheterisation or coronary angiography. After a negative result on testing for ischaemia, the patient can then be safely discharged. It would be interesting to see if a six hour period of observation could be substituted for our current 9-12 hours. But to assert confidently that a patient is at low risk of coronary disease and poor outcome, this study would have to include a larger patient population, the gold standard of coronary imaging, and careful follow up of patients for adverse outcomes.

Carl E Palffy director

Chest Pain Evaluation Unit, St Joseph Mercy Hospital, Pontiac, MI 48321, USA palfmd@aol.com

1 Herren KR, Mackway-Jones K, Richards CR, Seneviratne CJ, France MW, Cotter L. Diagnostic cohort study. Is it possible to exclude a diagnosis of myocardial damage within six hours of admission to an emergency department? $B M I$ 2001:323:372. (18 August.) 


\section{Integrating genetics into primary care in practice}

EDITOR-Emery and Hayflick continued the debate on integrating genetic medicine into primary care. ${ }^{1}$ We agree that primary care will identify people at genetic risk and help manage known risk not only for the patient but also for other family members. Emery and Hayflick define clear roles for primary care practitioners and draw on qualitative studies to claim that they are accepted roles of primary care.

But they cite only one study and overlook those that challenge their position-for example, Kumar and Gantley, and Elwyn et al. ${ }^{23}$ In the former general practitioners knowledgeable about genetic advances resisted taking on many of the tasks Emery and Hayflick identify for general practitioners because of ethical dilemmas associated with the therapeutic gap in the context of common cancers. In the latter, practitioners working in deprived communities questioned the validity of unearthing genetic risk issues when other more practical and demand led problems took priority. ${ }^{3}$

We agree with Emery and Hayflick that primary care must be prepared for the potential impact of genetics on clinical practice. We believe, however, that the focus should not be solely on becoming genetic technicians but on how to interpret genetic risk in the context of specific environments and socioeconomic conditions. Sex, ethnic group, and geography also need to be factored into this debate in a more realistic fashion. This will require systems in which patients' biological and socioeconomic risks are recorded together and considered concurrently. This is important if we are to avoid deterministic practice which risks overestimating predisposition to disease, and underestimating the contribution of socioeconomic inequalities, and a person's capacity to influence his or her medical history.

General practice uniquely combines biomedical knowledge and an understanding of the social construction of illness-or the threat of illness-in the patient's life. ${ }^{4}$ The debate on genetic medicine in primary care will be the richer for considering the expertise of both generalists and specialists.

Satinder Kumar senior research fellow University of Southampton, Department of Primary Care, Southampton SO16 5ST skk@soton.ac.uk

Madeleine Gantley medical anthropologist Rue Chatelain, B-1050 Brussels, Belgium

Glyn Elwyn senior lecturer

Department of General Practice, University of Wales College of Medicine, Cardiff CF23 9PN

Rachel Iredale senior lecturer

School of Care Sciences, University of Glamorgan, Pontypridd, Wales CF37 1DL

1 Emery J, Hayflick S. The challenge of integrating genetic medicine into primary care. BMJ 2001;322:1027-30. (28 April.)

2 Kumar S, Gantley M. Tensions between policy makers and general practitioners in implementing the new genetics: general practitioners in implementing the new genetic:
grounded theory interview study. BMJ 1999;319:1410-3.
3 Elwyn G, Iredale R, Gray J. Introducing a triage controlled referral system for cancer genetics across Wales an checking "acceptability" in general practice. Fam Pract (in press).

Heath I, Evans P, van Wheel C. The specialist of the discipline of general practice. BMJ 2000;320:326-7.

\section{Depressed mood during pregnancy and after childbirth}

Time points for assessing perinatal mood must be optimised

EDITOR-Evans et al studied perinatal mood using the Edinburgh postnatal depression scale. ${ }^{1}$ They claim that symptoms of depression are not more common or severe after childbirth than during pregnancy and that depression during pregnancy is more common than postnatal depression. These two findings have potentially far reaching implications, but caution is needed in using the data to draw these conclusions.

The Edinburgh postnatal depression scale has been validated for use only in the early postpartum period and predicts depression correctly in most $(73 \%)$ women with a score above 12. ${ }^{2}$ Analysis of scores below this threshold should be made with care: variability of 1-2 points then has not been proved to indicate severity of depression. The interpretation of raised mean scores (such as 6.72 at 32 weeks of pregnancy compared with 5.84 at 8 weeks post partum) as indicating more severe depression may then be inaccurate. The difference in mean scores should be considered with respect only to those scores above 12 , but the authors did not do this. Instead they evaluated change in average score.

Factors assessed by checklists of depressive symptoms tend to be associated with many psychiatric disturbances, including anxiety and related stresses such as adverse living conditions. ${ }^{3}$ Thus non-specific stressors leading to higher levels of anxiety could transiently increase a woman's score on the Edinburgh postnatal depression scale at any time. Two of the time points chosen (18 and 32 weeks of pregnancy) coincide with times of contact with staff for antenatal screening and discussion of the birth plan. Having to consider these choices adds to mounting anxiety secondary to many factors, including experience of the pregnancy as a loss of control and anticipation of a major life transition.

The study found more women to be depressed at 32 weeks of pregnancy than at 8 weeks post partum. There may, however, be a higher frequency of postpartum depression before 8 weeks that the study did not detect. Postpartum depression presents most commonly within a month of childbirth; swift recognition and appropriate treatment would lead to an improvement in symptoms by 8 weeks post partum.

The authors are right to highlight the importance of assessing perinatal mood, but the times for administering the Edinburgh postnatal depression scale should be carefully selected to avoid a false picture being given.
Julia Lappin senior house officer in psychiatry Maudsley Hospital, London SE5 8AZ julia_lappin@hotmail.com

1 Evans J, Heron J, Francomb H, Oke S, Golding J, on behalf of the Avon Longitudinal Study of Parents and Children Study Team. Cohort study of depressed mood during pregnancy and after childbirth. BMJ 2001:323:257-60. pregnancy

2 Cox JL, Holden JM, Sagovsky R. Detection of postnatal depression-development of the 10-item Edinburgh postnatal depression scale. BMJ 1987;150:782-6.

natal depression scale. BMy 1987;150:78 Garrison WT, Earls FJ. Epidemiological perspectives on maternal depression and the young child. In: Field T, Tronick EZ, eds. Maternal depression and child development. San Francisco: Jossey-Bass, 1986:13-30. (New develop-
ments for child development No 34.)

Treatment for depression is important confounding variable

EDITOR-Evans et al reported that scores on the Edinburgh postnatal depression scale were higher during pregnancy than at 8 weeks or 8 months post partum. ${ }^{1}$ No information is provided, however, on the number of women in the postpartum group who were receiving treatment for depression. Treatment includes both pharmacological and non-pharmacological means. The absence of this information brings the results of the study into question.

The effect of treatment is an important confounding variable. During pregnancy women are reluctant to take antidepressant drugs; after the birth, however, many will have already attended their general practitioners and have started treatment by 8 weeks post partum, when the postnatal depression score was measured. The conclusion that symptoms of depression are not more common or severe after childbirth than during pregnancy cannot be supported unless information regarding numbers of women receiving treatment for depression are included.

J Sheehan consultant in liaison psychiatry Rotunda Hospital, Dublin 1, Republic of Ireland

F M Crotty special lecturer in psychiatry Mater Misericordiae Hospital, Dublin 7 fcrotty@mater.ie

1 Evans J, Heron J, Francomb H, Oke S, Golding J, on behalf of the Avon Longitudinal Study of Parents and Children Study Team. Cohort study of depressed mood during pregnancy and after childbirth. BMJ 2001;323:257-60. (4 August.)

Data do not support idea that depression is more common antenatally than postnatally

Editor-In Evans et al's study both the total scores on the Edinburgh postnatal depression scale and the number of women scoring above 12 rose through pregnancy and fell after delivery. ${ }^{1}$ The authors are generally careful not to use the terms depression and illness but refer to depressive symptoms. They acknowledge that a cut-off score on a screening schedule does not give a clinical diagnosis, but this caution is abandoned in their conclusion-that antenatal depression is commoner than postnatal depression and that treatment would benefit the mother and infant. This was widely quoted in the media on the morning of publication.

The findings do not support this conclusion, showing only that scores on the 
depression scale rise during pregnancy. In the absence of normative data on common emotional changes during pregnancy, and the properties of items on the scale in relation to established dimensions of perinatal depressive illness, we cannot ascertain how many women had a depressive episode that required treatment. This is highlighted by the observation that half of the women who scored above the threshold at 32 weeks scored below it at 8 weeks post partum, presumably without treatment.

The comment that the benefits of antidepressants may outweigh the risks in pregnancy could be seen to encourage their use in late pregnancy. Although the risks of teratogenesis are low, there is no evidence on the safety of antidepressants in late pregnancy.

An alternative and simpler explanation for rising scores during pregnancy is that certain items on the Edinburgh postnatal depression scale pick up common concerns in pregnancy. For example, item four relates to feeling worried and anxious for no good reason, while item six relates to coping less well than usual. We are concerned that nonspecialist readers will misunderstand this study as relating to depressive illness severe enough to require specialist treatment. To state that serious depressive disorder is more common and more severe antenatally than postnatally is not supported by these data.

What the authors have shown is the need for rigorous clinical research into the relation between cut-off scores on screening schedules and the nature of depressive disorder. The possible treatment needs of those identified with screening schedules should also be investigated.

M R Oates senior lecturer in perinatal psychiatr University Hospital, Queens Medical Centre, Nottingham NG7 2UH

Margaret.Oates@nottingham.ac.uk

A Lee consultant psychiatrist

University Hospital, Nottingham NG7 2UH

1 Evans J, Heron J, Francomb H, Oke S, Golding J, on behalf of the Avon Longitudinal Study of Parents and Children Study Team. Cohort study of depressed mood during pregnancy and after childbirth. BMJ 2001;323:257-60. (4 August.)

\section{Authors' reply}

EDITOR-We agree that scoring above a threshold on the Edinburgh postnatal depression scale is not the same as being diagnosed as having depression. The scale has been validated during pregnancy against a standardised clinical interview, and we referred to this in the paper. ${ }^{1}$ The scale therefore gives a reasonable estimate of the prevalence of depression during pregnancy and does not just detect minor emotional fluctuations.

The mean individual item scores do not differ between pregnancy and the postpartum period, and more women have high or very high scores during pregnancy than after childbirth. Lappin suggests comparing mean scores only for those above the threshold for depression during pregnancy and after childbirth; these scores were 15.57 at 32 weeks of pregnancy and 15.85 at 8 weeks post partum, which suggests no difference in severity of depression between these two times.

There is no evidence of discontinuity between depressive symptoms and depressive disorder in general populations. ${ }^{2}$ A scale may give a better indication of severity than a clinical diagnosis: the range of severity is considerable even within the category major depressive disorder. Validation studies of the Edinburgh postnatal depression scale indicate that scores differ between people with minor, moderate, and major depressive disorder, and the scale was also sensitive to change in the severity of depression over time.

Our statement that the benefits of using antidepressants might outweigh the risks for women with severe depression does not encourage the use of antidepressants during pregnancy without careful consideration. We have highlighted the need for research into safe and effective treatments of depression during pregnancy as well as the consequences of untreated depression at this time.

Two letters point out that treatment of postpartum depression may have been partly responsible for our apparently lower rates of depression in this period. Although this is possible, we think it is unlikely that depression would have been recognised and responded to so quickly. Only $0.6 \%$ of all mothers were taking antidepressants post partum and were below the threshold for depression at 8 weeks post partum. Even if we assume that all of these would have been above the threshold at 6 weeks post partum there would still be fewer above the threshold post partum than at 32 weeks of pregnancy.

Finally, the timing of the measures, as pointed out, coincided with obstetric care. Scores may certainly have been higher or lower at other times, but for the purposes of screening these times are the most practica to use.

We are confident that our paper emphasises that symptoms of depression are more common during pregnancy. It is important that general practitioners, health visitors, and others are aware that pregnant women are not protected from common mental disorder

Jonathan Evans consultant senior lecturer Division of Psychiatry, University of Bristol, Bristol BS2 8DZ

j.evans@bristol.ac.uk

Jon Heron research assistant

Jean Golding professor of paediatric epidemiology Unit of Paediatric and Perinatal Epidemiology, Division of Child Health, University of Bristol, Bristol BS8 1TQ

Helen Francomb midwife

Department of Women's Health and Care of the Newborn, North Bristol NHS Trust, Southmead Hospital, Bristol BS10 5NB

Sarah Oke consultant psychiatrist

Mother and Baby Unit, Barrow Hospital, Barrow Gurney, Bristol BS48 3SG

On behalf of the Avon Longitudinal Study of Parents and Children (ALSPAC) Study Team.

1 Thorpe K. A study of the Edinburgh postnatal depression
scale for use with parent groups outside the postpartum
period.J Reproduct Infant Psychol 1993;11:119-25.
2 Goldberg D, Huxley P. Common mental disorders: a bio-social model. London: Tavistock, 1992

\section{Patients and medical power}

\section{More debate about patient power in NHS} is needed

EDITOR-Canter raises important points about the problematic nature of power and the idea that it can simply be shifted from one party to another, particularly given the asymmetries of knowledge and skill that are structurally inherent in professional-client relationships. ${ }^{1}$ However, his challenge to Alan Milburn, the health minister, stops short of the crucial question about whether a national health service should seek to achieve a "decisive shift of power in favour of the patient." The potential implication of this statement-that doctors should simply give patients what they want-is fundamentally incompatible with the ethics of taxation.

As Canter's analysis hints but does not explicate, Milburn's statement implies that doctors should prescribe unnecessary antibiotics, carry out unnecessary surgery, and make available untested treatments-all in the name of patient power. Where does this leave the simultaneous investment in the National Institute for Clinical Excellence, evidence based medicine, and medicines management? More to the point, where does it leave the NHS on the morality of its funding from tax levies?

In an insurance based system I can choose to pay for the level of access that I want. If I want a consumer driven system that gives me absolute freedom of choice then I can pay for it, at least to the extent that I can afford the premiums or can persuade others to join me in a risk pool where we each agree to fund the others' unlimited choices.

In a tax funded system we must consider the ethics of compulsorily levying all taxpaying citizens and whether this can ever be justified beyond the extent of providing demonstrably efficient and effective care to those citizens. Doctors are the agents of restraint on behalf of taxpayers.

As a patient, I may want the NHS to do everything for me that may be of any conceivable benefit or that will, at least, make me feel good about it. As a taxpayer, I do not want to see my income sequestered to indulge the fancies of others when there is a clear medical view that an intervention has no clear and established benefit. It is a politician's duty to manage that conflict and the medical profession's task to produce practical resolutions in individual cases.

Loose talk about shifts in power is just that and should give way to the more sophisticated debate that Canter is seeking to encourage.

Robert Dingwall professor of sociology University of Nottingham, Nottingham NG7 2RD robert.dingwall@nottingham.ac.uk

1 Canter R. Patients and medical power. BMJ 2001;323:414. (25 August.) 


\section{Patient power requires patient freedom}

EDITOR-Canter's editorial highlighted the formal difficulty in promoting patients' power. ${ }^{1}$ I see this in a social context and have summarised some of the problems here (a longer version of this letter can be found at bmj.com/cgi/eletters/323/7310/

414\#EL14).

- Medical power is intrinsic to medicine. It cannot be handed over

- Medical power is a particular aspect of "experts' power"

- Medical power arises from the process of socialisation, which induces submission to medicine (we are born in hospital, vaccinated, surveyed while children, and screened while adults; medical examinations are requested for employment and insurance and other purposes; and most of us will die in hospitals)

- The patient's entourage undergoes the same process of socialisation, and patients' relatives are a major source of pressure for medical power to be enforced

- The politicisation of medical power removes power from the doctor-patient interface and gives it to higher administrative levels (the government and committees (health authorities, the National Institute for Clinical Excellence, etc))

- Lobbying groups, while requesting more power for patients, result in more power being moved away from the patient to higher administrative levels

- It is a fallacy that medical power is handed over to the patient through being more strictly enforced, with the role of guidelines and protocols being reinforced and the leeway for personal variance being decreased

- The current discussion cannot look outside the Western medical paradigm, and medical advice can only be opposed by even more authoritative medical opinions. Such opinions are handed over from somewhere further from the patient (the problem of applying evidence from populations to particular individuals being bypassed through the unquestioning acceptance of the said paradigm).

The constraints on patients' power arise from social conditioning to submit to medicine $^{2}$ and from political constraints on access to doctors of the patient's choice. Patients' power cannot be handed down from doctors; it has to be created anew through freedom to choose the doctor one wants to see; freedom of access to second or third opinions (not theoretical access, but economically and socially feasible access); and, above all, freedom to refuse the medical view of the world and choose alternative discourses and practices. When will a sick note from a non-orthodox medical practitioner become acceptable for sick pay?

J Calinas-Correia medical practitioner

16 Roskear, Camborne TR14 8DN

j_calinas@yahoo.co.uk

1 Canter R. Patients and medical power. BMJ 2001;323:414

2 Illich I. Limits to medicine. London: Marion Boyars, 1995.

Antenatal screening for HIV in National Blood Service

\begin{tabular}{lccc} 
Transfusion centre & Total No of samples & No (\%) screened for HIV & No (\%) positive for HIV \\
\hline Birmingham & 33292 & $18996(57)$ & $6(0.03)$ \\
\hline Oxford & 9280 & $5420(58)$ & $8(0.15)$ \\
\hline East Anglia & 8376 & $6993(83.5)$ & $1(0.01)$ \\
\hline Leeds & 10891 & $4089(37.5)$ & $4(0.09)$ \\
\hline Trent & 32884 & $16700(50.8)$ & $8(0.05)$ \\
\hline Total & 94723 & $52198(55)$ & $27(0.05)$ \\
\hline
\end{tabular}

Issue of power is almost irrelevant for doctors practising patient centred medicine

EDITOR-In the communication skills programme at the Imperial College of Science, Technology and Medicine, our first year medical students participate in a session titled "Power and adherence in the doctorpatient relationship." The issues raised by Canter are debated, specifically in relation to the models of power that he described. ${ }^{1}$ Among other things, the students usually identify the fact that decisions about medical treatment are rarely made in isolation.

Patients may consult several doctors or other members of the healthcare team, or both, so that a range of views, at least within the context of Western scientific medicine, can be elicited. The patient's decisions are also influenced by his or her world outside the consultation-by social, economic, religious, and cultural factors. The models of power tend to assume that only two parties are involved and do not consider additional influences to decision making.

If doctors are practising patient centred medicine then the issue of power is almost irrelevant. Patient centredness implies that the doctor will actively seek to determine the patient's desire to make decisions about his or her care in the same way that the amount of information that the patient wants about his or her illness should be assessed. A patient centred approach to medical care thus assumes that each patient is wielding the amount of power that he or she would wish to in the doctor-patient relationship.

Debra Nestel lecturer in communication skills Faculty of Medicine, Imperial College of Science, Technology and Medicine, London W2 1PD d.nestel@ic.ac.uk 1 Canter R. Patients and medical power. BMJ 2001;323:414.
(25 August.)

\section{National Blood Service can provide useful data for antenatal detection of HIV}

EdTor-Cliffe et al investigated the value of antenatal screening for HIV and the role it has in reducing perinatal transmission of HIV. ${ }^{1}$ The National Blood Service offers antenatal HIV screening linked to its traditional antenatal red cell serology service, and consequently it can provide useful data in a timely fashion on the prevalence of this infection in the antenatal population of England. We have analysed such data for women whose antenatal blood samples were received in the first eight months of 2001 by the five participating transfusion centres (Birmingham, Oxford, East Anglia, Leeds, and Trent). In total, blood samples were received from 94723 pregnant women. Of these, 52198 (55\%) consented to have an HIV test, and 27 $(0.05 \%)$ of them tested positive for HIV (table).

Further data on those infected were available only from the first three centres. Of the 15 HIV positive women detected by those laboratories only one was known to be HIV positive before her pregnancy. The major risk (9/15) associated with positivity was that the woman had moved to England from Africa (six from Zimbabwe). Of three HIV positive white women, one had a partner from Zimbabwe, one an AfroCaribbean partner born in the United Kingdom, and one a bisexual partner. Three women were Afro-Caribbean born in the United Kingdom. One of these had a partner who had recently come from the Caribbean, the status of the other two partners is not known.

The number of women detected in the first eight months of this year (27) greatly exceeds the six reported for 1999 in the paper by Cliffe at al, and the increased uptake of HIV screening since health service circular HSC 1999/183 should have a notable impact on reducing mother to baby transmission of HIV. ${ }^{2}$

Elizabeth Boxall consultant virologist National Blood Service, Birmingham B16 2SG

John Kurtz consultant virologist

National Blood Service, John Radcliffe Hospital, Oxford OX3 9DU

On behalf of the antenatal screening laboratories of the National Blood Service.

1 Cliffe S, Tookey PA, Nicoll A. Antenatal detection of HIV: national surveillance and unlinked anonymous survey. BMJ 2001;323:376-7.(18 August.)

2 Department of Health. Reducing mother to baby transmission of HIV. London: DoH, 1999. (HSC 1999/183.)

\section{Incentive payments may reduce time for clinical care}

EDITOR-Incentive payments for primary care are focused on either outcome or process, and the intervention on smoking studied by Coleman et al is an example of an outcome incentive. ${ }^{1}$ Such incentives change behaviour only if the primary care team believes that they can have an appreciable effect on outcome. Interventions on smoking lead to between $5 \%$ and $30 \%$ of people stopping smoking, but this depends on each patient being at the stage of contemplating 
change. ${ }^{23}$ An outcome incentive for smoking will therefore favour efforts to record who gives up smoking rather than efforts to encourage people to give up.

Process incentives can be more effective than outcome incentives when the outcome depends largely on factors outside the doctor's control. But they will change clinical behaviour only if the process is close to good clinical practice and is recognised to have benefit-for example, asking about contraception, which is likely to prevent pregnancies. In contrast, measuring peak flow in every asthmatic patient every year will not alter symptoms for more than a few patients with brittle asthma, who would probably be measuring peak flow already. Incentives like this seem to have been chosen because they can be easily verified rather than because they are clinically effective.

Incentives should fulfil the criteria for acceptance of a screening test. To produce change incentive payments should also be made for a specific process that is clearly effective, simple, and easy to record and fits with good clinical practice. Sadly, most of medicine does not come neatly packaged like this. As has been shown in reviews of interventions, there are few "magic bullets." ${ }^{35}$ In addition, if a payment is to be a true incentive it should cover the full cost of setting up the process and provide additional funds that can benefit other aspects of primary care.

Coleman et al state, "the path of least resistance to claim ... [incentives is often] ... simple administrative changes rather than changes in clinical behaviour." Attempts to change the behaviour of doctors in general practice have led to a system of mechanistic hoop jumping, which has resulted in an increasing administrative workload and a reduction in the time for clinical care.

Mark Rickenbach general practitioner Park Surgery, Chandlers Ford, Hampshire SO53 2ZH

rick@chandlers.prestel.co.uk

1 Coleman T, Wynn AT, Stevenson K, Cheater F. Qualitative study of pilot payment aimed at increasing general practitioners' antismoking advice to smokers. $B M$ 2001;323:432-5. (25 August.)

2 Prochaska J, DiClemente C. Treating addictive behavior:processes of change. New York: Plenum, 1986.

3 Prochaska JO, Velicer WF, Rossi JS, Goldstein MG, Marcus $\mathrm{BH}$, Rakowski W, et al. Stages of change and decision $\mathrm{BH}$, Rakowski $\mathrm{W}$, et al. Stages of change and decisiona balance for 12 problem behaviours. Health Psychol
1994;13:39-46.

Oxman AD, Thomson MA, Davis DA, Haynes RB. No magic bullets: a systematic review of 102 trials of interventions to help health care professionals deliver services more effectively and efficiently. Can Med Assoc J 1995;153:1423-31

5 Wensing M, Grol R. Single and combined strategies for implementing change in primary care: a literature review. Int J Qual Health Care 1994;6:115-32.

\section{Law of supply and demand applies in NHS}

EDITOR-So recognisable was Jeffrey's description of his wife's doctor's surgery that I read his end piece with discomfort, as I had a strong suspicion that his wife was a patient of mine. ${ }^{1}$
I was pleased to discover that it was not our service being described, but I was also interested because I had made the same comparisons between my surgery and the local veterinary surgery when my own cat had been unwell. I had found consolation in the argument that, as a public service, the NHS does not have the same laws of supply and demand that the private sector vets have. If a vet's workload rises, I thought, then so does their income. With that they can employ more vets without the approval of the veterinary equivalent of the Medical Practices Committee, and thus maintain a similar level of service no matter what the demand.

My consolation was stolen from me, ironically on the day before I read the end piece, by a friend not employed in health care at all. He pointed out that the law of supply and demand has to work in the NHS, because it is a universal law that has to work everywhere, but I was looking at it from the wrong point of view. I had said the law doesn't work, because I cannot increase the supply just because the demand increases. But in the world of business, if the demand increases and the supply does not, the price rises. This integral part of the supply and demand law is already working in the NHS. Granted, people are not paying money to see me (yet), but the cost, in terms of time spent in the waiting room, quality of public address system, length of consultation, time spent waiting for an appointment, hospital waiting lists etc, has been rising for as long as I can remember.

In the months and years to come, particularly if a majority of general practitioners decide to resign their NHS contracts next April, the public, politicians, and the profession will have to negotiate how this price is to be paid. It will be many years before we are in the position that our veterinary colleagues are in and simply take on new staff. Given that, the price must continue to rise for as long as the demand does. Would Jeffrey be happier with the status quo, or would he prefer that his wife see my receptionist for the bill on the way out?

Tim Heywood general practitioner

Hagley Surgery, Hagley DY9 0NH

big.tim@lineone.net

1 Jeffrey D. Memorable patients: Those who sit and wait. BMJ 2001;323:362. (18 August.)

\section{Social exclusion must be considered in global terms}

EDITOR-The BMJ announced that the issue of 28 July would be dedicated to social exclusion. Given the journal's global readership, this generated many expectations: the underlying causes of patients' ills are not often the subject of commentary in the medical literature. The papers in the issue presented some of the British experience and one study from outside the United Kingdom. ${ }^{1}$
The $B M J$ has a tradition of attending to neglected medical topics, including poverty and access to drugs for HIV infection and AIDS. It also gives free access on the internet, thereby ending another sort of exclusion (lack of access to medical information in the settings in which burdens of disease are greatest). Beyond the borders of wealthy industrialised countries a substantial majority of all people are excluded from ready access to modern medical care. If the $B M J$ wants to continue in this internationalising vein (the title of the Editor's choice for the issue of 11 August was "Aspiring to be global") the analysis of international health matters should be deeper still, even if this requires more special theme issues.

One way of lessening exclusion is to hear the voices of the millions who are excluded not only from access to care but from access to a forum in which their exclusion is acknowledged. Are those on the receiving end of these lamentable conditions included in the definition of social exclusion or are they, in fact, excluded from the visibly excluded? Does one have to move to an industrialised country to have one's plight acknowledged? What are the boundaries of "our society" as used in the definition of social exclusion?

Exclusion is a concept that is supplanting older terms, from "oppressed" to "underclass." But it has not always been used in a sociologically or historically honest manner. Analysis of social exclusion in this global era will necessarily be transnationalotherwise, the growing outcome gap between the haves and have nots will be seen as a strictly national problem. Doctors know that the diseases we treat, or attempt to prevent, do not recognise such boundaries.

Linking analysis of exclusion to the conviction that access to health care should be a fundamental human right is the most sound means of moving towards inclusion. We would encourage editors to take a critical look at even the concept of social exclusion, which often becomes code for exclusions within an affluent society.

J Jaime Miranda

EDHUCASalud, Civil Association for Health and Human Rights Education, Apartado Postal 9, Ayacucho, Peru jjmiranda@terra.com.pe

Paul Farmer

Program Infectious Diseases and Social Change, Harvard Medical School, Partners in Health, Boston, MA 02115, USA

1 Editor's choice. Social exclusion: old problem, new name BMJ 2001;323 (7306). (28 July.)

2 Editor's choice. Aspiring to be global. BMJ 2001;323 (7308). (11 August.)

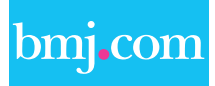

\section{Rapid responses}

Correspondence submitted electronically is available on our website 